\title{
APROVECHAMIENTO DE ALMIDÓN DE CEBADA DE MALA CALIDAD PARA LA PRODUCCIÓN DE ENZIMAS AMILOLÍTICAS POR Aureobasidium pullulans
}

(Use of low quality barley starch for the production of amylolytic enzymes by Aureobasidium pullulans)

\author{
María Isabel HERNÁNDEZ-CASTILLO ${ }^{1}$, Angélica HERNÁNDEZ-NAVARRETE ${ }^{1}$, \\ Fabiola Eloísa JIMÉNEZ-MONTEJO ${ }^{1}$, María del Carmen CRUZ-LÓPEZ ${ }^{1}$, \\ María Eugenia HIDALGO-LARA² y Víctor Eric LÓPEZ Y LÓPEZ ${ }^{1 *}$
}

${ }^{1}$ Centro de Investigación en Biotecnología Aplicada del Instituto Politécnico Nacional, km 1.5 carretera estatal Santa Inés Tecuexcomac-Tepetitla, 90700 Tepetitla de Lardizábal, Tlaxcala, México

${ }^{2}$ Departamento de Biotecnología y Bioingeniería del Centro de Investigación y de Estudios Avanzados del Instituto Politécnico Nacional, Av. Instituto Politécnico Nacional 2508, Col. San Pedro Zacatenco, 07360 Ciudad de México, México

*Autor para correspondencia: vlopezyl@ipn.mx

(Recibido octubre 2017; aceptado agosto 2018)

Palabras clave: sacarificación, glucoamilasa, $\alpha$-amilasa, $\alpha$-glucosidasa, $\beta$-glucosidasa

\section{RESUMEN}

La cebada de baja calidad rechazada para el proceso de producción de malta puede ser utilizada para la obtención de productos de valor agregado, particularmente enzimas. En este trabajo se extrajo almidón de cebada y se usó para producir enzimas amilolíticas por Aureobasidium pullulans. Utilizando $50 \mathrm{~g} / \mathrm{L}$ de almidón, se produjeron glucoamilasa, $\alpha$-amilasa, $\alpha$-glucosidasa y $\beta$-glucosidasa con actividades máximas de 193, 7.4, 8.1 y $8.5 \mathrm{U} / \mathrm{mL}$, respectivamente. A las $30 \mathrm{~h}$ de fermentación se obtuvo un extracto enzimático crudo que se utilizó para sacarificar almidón de tres fuentes a $10 \mathrm{~g} / \mathrm{L}$ : cebada, soluble (papa) y maíz. Primero, fueron evaluados dos medios de reacción (agua y solución tampón de acetato) y la adición de calcio $\left(\mathrm{Ca}^{2+}\right)$. Posteriormente, se evaluó la gelatinización del almidón y finalmente se realizaron experimentos aumentando la concentración de almidón $(50$ a $400 \mathrm{~g} / \mathrm{L})$. El agua y la adición de $\mathrm{Ca}^{2+}$ tuvieron un efecto positivo, resultando una concentración máxima de glucosa de 3.84, 0.84 y 0.4 $\mathrm{g} / \mathrm{L}$ para almidón de cebada, soluble y de maíz, respectivamente. La gelatinización del almidón fue positiva para el almidón soluble y de maíz, aumentando la hidrólisis en 23 y $25 \%$, respectivamente. El incremento de la concentración de almidón a 50 $\mathrm{g} / \mathrm{L}$ fue la mejor condición; aumentó la hidrólisis en 3.2, 40 y $42 \%$ para almidón de cebada, soluble y de maíz, respectivamente. Este trabajo demuestra que el almidón de cebada de baja calidad puede ser aprovechado para la obtención de productos de valor agregado, como las enzimas.

Key words: saccharification, $\alpha$-amylase, glucoamylase, $\alpha$-glucosidase, $\beta$-glucosidase 


\begin{abstract}
Low quality barley that has been rejected for the malt production process can be used to produce value added products, particularly enzymes. Hence, in this work the starch was extracted and used to produce amylolytic enzymes by Aureobasidium pullulans. Using $50 \mathrm{~g} / \mathrm{L}$ of barley raw starch, glucoamylase, $\alpha$-amylase, $\alpha$ glucosidase and $\beta$-glucosidase enzymes were produced with maximum activities of 193, 7.4, 8.1 and $8.5 \mathrm{U} / \mathrm{mL}$, respectively. After $30 \mathrm{~h}$ of fermentation a crude extract was obtained, which was used as enzymatic source for the saccharification of starch from three sources at $10 \mathrm{~g} / \mathrm{L}$ : barley, soluble (from potato) and corn. First, two reaction solvents (water and acetate buffer) and the addition of calcium $\left(\mathrm{Ca}^{2+}\right)$ were evaluated. Afterwards, starch gelatinization was evaluated and finally experiments varying the starch concentration (from 50 to $400 \mathrm{~g} / \mathrm{L}$ ) were conducted. Using water as solvent and the $\mathrm{Ca}^{2+}$ addition had a positive effect, resulting in a maximum glucose concentration of 3.84, 0.84 and $0.4 \mathrm{~g} / \mathrm{L}$ from barley, soluble and corn starches, respectively. In the other hand, starch gelatinization was positive for soluble and corn starches, enhancing hydrolysis in 23 and $25 \%$, respectively. Increasing the starch concentration to $50 \mathrm{~g} / \mathrm{L}$ was the best condition, enhancing hydrolysis in 3.2, 40 and $42 \%$ from barley, soluble and corn starches, respectively. This work demonstrates that low quality raw barley starch can be used for the production of value added products such as enzymes.
\end{abstract}

\section{INTRODUCCIÓN}

Los productos obtenidos a partir de fuentes renovables, como los residuos agroindustriales o materias primas de bajo costo, son de especial interés debido a que permiten aminorar el impacto ambiental reduciendo fuentes de contaminación o bien los costos en el tratamiento y disposición de dichos residuos en la industria. En décadas anteriores se ha buscado una oportunidad de aprovechamiento tanto de residuos como de materias primas que no cumplen con los requerimientos necesarios para procesos industriales. Un ejemplo de esto es la cebada maltera, la cual debe cumplir con especificaciones y parámetros para ser utilizada en el proceso de malteo dentro de la producción de cerveza, ya que éste es su único mercado en el país (Aguilar y Schwentesius 2004). En México, de acuerdo con la Organización de las Naciones Unidas para la Alimentación y la Agricultura (FAO 2018), desde hace varias décadas se incrementó la producción de cebada maltera. Según datos del Servicio de Información Agroalimentaria y Pesquera (SIAP 2018) hasta fines de 2017, los principales estados productores de cebada maltera fueron Guanajuato (369 176 t), Hidalgo (240 283 t), Tlaxcala (87 351 t), Puebla (84 615 t) y el Estado de México (50 836 t), representando el $37,24,9,8.4$, y $5 \%$ de la producción nacional, respectivamente.

De acuerdo con la norma NMX-FF-043SCFI-2003 (SEECO 2003), una cebada de buena calidad debe cumplir con varias especificaciones: humedad (11.5 y $13.5 \%)$, germinación mínima (85\%), grano dañado (máximo $10 \%$ ), peso hectolítrico mínimo (de 56 y $58 \mathrm{~kg} / \mathrm{hL}$ para cebada de seis y dos hileras, respectivamente), y parámetros como color, olor y tamaño, los cuales son dependientes de las condiciones medioambientales que prevalecen durante el desarrollo y maduración del grano. Sin embargo, en México, cada año grandes cantidades de cebada que no cumplen con dichas especificaciones y parámetros son rechazadas por la industria maltera. Esta cebada de baja calidad no tiene prácticamente otro nicho de mercado, y suele ser utilizada como alimento para ganado (Aguilar y Schwentesius 2004).

Por otra parte, diversos tipos de residuos agroindustriales con alto contenido de celulosa, hemicelulosa, xilano, lignina y pectina, como el bagazo de caña, residuos de uva, cáscara de avena y trigo, entre otros, se han utilizado como sustratos para la producción y evaluación de sistemas enzimáticos, principalmente aquellos que son inducibles como las celulasas (Botella et al. 2005), las xilanasas, las proteasas (Oliveira et al. 2006), las pectinasas (Castilho et al. 2000) y las lipasas (Godoy et al. 2009). En el caso de la cebada es posible aprovechar el almidón, que representa en promedio 53 $\%$ del peso del grano (Vasanthan y Hoover 2009), para obtener productos de valor agregado como enzimas amilolíticas de importancia industrial.

Djekrif et al. 2015 reportaron que levaduras como Cryptococcus, Trichosporon, Saccharomycopsis, Lipomyces, Candida, Rhodotorula, Clavispora, Filobasidium y Aureobasidium producen enzimas 
amilolíticas tales como $\alpha$-amilasas, glucoamilasas, glucosidasas, pululanasas y ciclodextrinasas, a partir de diferentes sustratos, y pueden ser aplicadas en la industria de la sacarificación del almidón. Aureobasidium pullulans produce al menos cuatro tipos de enzimas amilolíticas extracelulares usando diferentes sustratos para su inducción (Saha et al. 1993).

A continuación, se describen: la glucoamilasa exoenzima que hidroliza los enlaces $\alpha-1,4$ y $\alpha-1,6$ para liberar D-glucosa a partir de almidón y polisacáridos similares (Sauer et al. 2000); la $\alpha$-glucosidasa, una exoenzima que hidroliza los enlaces $\alpha-1,4$, liberando glucosa, de manera menos eficiente que la glucoamilasa (Tomasik y Horton 2012); la $\beta$-glucosidasa, una endoenzima que hidroliza los enlaces $\beta$-glucosídicos de la estructura interna del almidón, liberando glucosa como principal producto (Hayashi et al. 1999); y la $\alpha$-amilasa, una endoenzima que cataliza la hidrólisis de los enlaces $\alpha-1,4$ glucosídicos en almidón, liberando productos de bajo peso molecular como glucosa, maltosa y maltotriosa (Demirkan et al. 2005). Las enzimas amilolíticas son de gran importancia en aplicaciones biotecnológicas, no sólo en la sacarificación de almidón, sino en diferentes industrias como la textil y la papelera (Gupta et al. 2003, Rana et al. 2013).

Por lo anterior, el objetivo de este trabajo fue la producción de enzimas amilolíticas usando la levadura $A$. pullulans a partir de almidón de cebada de baja calidad como sustrato y su aplicación en la sacarificación de almidón proveniente de distintas fuentes, en diferentes condiciones de temperatura, tiempo y concentración de sustrato para la producción de glucosa.

\section{MATERIALES Y MÉTODOS}

\section{Aislamiento de almidón a partir de granos de cebada}

La cebada (Hordeum vulgare) de baja calidad se obtuvo con un productor local en el estado de Hidalgo, México. La etapa de limpieza consistió en retirar las impurezas de mayor tamaño (piedras, restos florales, otros granos, etc.). Posteriormente se realizó un proceso de perlado, el cual consistió en hacer pasar el grano de cebada por una licuadora industrial durante $50 \mathrm{~s}$, para retirar la cascarilla y obtener un grano íntegro. El aislamiento de almidón se realizó de acuerdo con Wang y Wang (2004), con algunas adecuaciones. La harina de cebada se obtuvo con un molino para granos y especias, ajustando la apertura de los discos para obtener un polvo ligeramente granulado, que fue macerado con hidróxido de sodio
$(\mathrm{NaOH})$ al $0.1 \%$ a una relación de $1: 2(\mathrm{~m} / \mathrm{v})$ durante $18 \mathrm{~h} \mathrm{a} 4^{\circ} \mathrm{C}$, para remover las proteínas y lípidos que se encuentran unidos a los gránulos de almidón y favorecer la separación (Uthumporn et al. 2012). La mezcla se hizo pasar por los tamices núm. 100 y 200 US lavando con agua destilada en cantidad necesaria para retirar todo el almidón. La suspensión obtenida se centrifugó 15 min a 9240 g y $4{ }^{\circ} \mathrm{C}$; a partir del pellet se separó el almidón, se secó a $30{ }^{\circ} \mathrm{C}$ por $24 \mathrm{~h}$ en un horno y se mantuvo a temperatura ambiente en un contenedor sellado (Bello et al. 2010).

Finalmente, se aplicó un pretratamiento con ácido clorhídrico $(\mathrm{HCl})$ al $6 \%$ para favorecer la hidrólisis durante las cinéticas de crecimiento. Se mezcló el almidón de cebada y $\mathrm{HCl}$ en una relación de $1: 3(\mathrm{p} / \mathrm{v})$, se ajustó el pH a 5.5 y se mantuvo en agitación durante $6 \mathrm{~h}$. Se centrifugó descartando el sobrenadante en las mismas condiciones descritas anteriormente, se dejó secar a temperatura ambiente, se molió en mortero y se conservó a temperatura ambiente para su posterior uso.

\section{Microorganismo y condiciones de cultivo a nivel matraz}

La cepa de la levadura Aureobasidium pullulans usada para la producción de enzimas amilolíticas fue ATCC $^{\circledR} 15233^{\mathrm{TM}}$. Para la propagación, se formuló un medio de cultivo ajustando la cantidad de almidón de cebada y fuente de nitrógeno $\left(\mathrm{NH}_{4} \mathrm{Cl}\right)$ para obtener tres relaciones carbono: nitrógeno $(\mathrm{C}: \mathrm{N})$ de $8,15 \mathrm{y}$ 20; adicionalmente, el medio contenía la siguiente composición en $\mathrm{g} / \mathrm{L}$ : 5 extracto de levadura, 0.2 $\mathrm{MgSO}_{4} \cdot 7 \mathrm{H}_{2} \mathrm{O}, 0.3 \mathrm{KH}_{2} \mathrm{PO}_{4}, 5 \mathrm{CaCO}_{3}$ y 0.001 tiamina. Los experimentos se realizaron en matraces Erlenmeyer con $250 \mathrm{~mL}$ de medio, se inocularon con células obtenidas de una placa de la levadura en medio agar papa dextrosa (PDA, por sus siglas en inglés) incubada a $30^{\circ} \mathrm{C}, 24 \mathrm{~h}$, recuperando las células, y se ajustaron en solución salina estéril a una cuenta celular de $5 \times 10^{7}$ células $/ \mathrm{mL}$. Los matraces se incubaron orbitalmente a $180 \mathrm{rpm}$ a $30{ }^{\circ} \mathrm{C}, \mathrm{pH}$ 5.5. Se tomaron muestras cada $12 \mathrm{~h}$, para realizar el conteo celular durante $48 \mathrm{~h}$. El crecimiento celular se cuantificó microscópicamente por duplicado en la cámara de Neubauer, diluyendo las muestras del medio de cultivo en solución salina, seguida de una agitación vigorosa en orden de evitar la sedimentación celular (Dinorín et al. 2015).

\section{Condiciones de cultivo a nivel reactor}

Las fermentaciones se realizaron en un reactor de 7 L Biostat ${ }^{\circledR}$ A Plus (Sartorius). El medio de cultivo tenía la siguiente composición en g/L: 50 almidón 
de cebada, $8.6 \mathrm{NH}_{4} \mathrm{Cl}, 5$ extracto de levadura, 0.2 $\mathrm{MgSO}_{4} \cdot 7 \mathrm{H}_{2} \mathrm{O}, 0.3 \mathrm{KH}_{2} \mathrm{PO}_{4}, 5 \mathrm{CaCO}_{3}$ y 0.001 tiamina. Las condiciones de operación del reactor fueron $4 \mathrm{~L}$ de medio, $30{ }^{\circ} \mathrm{C}$, agitado a $600 \mathrm{rpm}$, $1.0 \mathrm{vvm}$ (volumen de aire por volumen de medio por minuto) y pH 5.5 controlado automáticamente con ácido fosfórico e hidróxido de sodio. El inóculo del reactor $(5 \% \mathrm{v} / \mathrm{v})$ se preparó a partir de una placa de PDA, inoculando $5 \times 10^{5}$ células $/ \mathrm{ml}$ a un matraz de $1.0 \mathrm{~L}$ con $200 \mathrm{~mL}$ de medio líquido basado en el almidón de cebada descrito anteriormente, incubando durante $18 \mathrm{~h}$ a $200 \mathrm{rpm}, 30^{\circ} \mathrm{C}$. Se tomaron muestras cada $3 \mathrm{~h}$ para los análisis de crecimiento celular y actividades enzimáticas.

\section{Obtención del extracto enzimático}

A las $30 \mathrm{~h}$ de fermentación se cosechó todo el cultivo y se centrifugó durante 15 min a 9240 g y $4{ }^{\circ} \mathrm{C}$ para eliminar las células y el almidón residual. El sobrenadante se filtró con una membrana de $0.45 \mu \mathrm{m}$ y posteriormente ultrafiltrado, con una membrana de $50 \mathrm{kDa}$. El extracto liofilizado $\left(0.016 \mathrm{mBar},-52^{\circ} \mathrm{C}\right)$ fue utilizado como fuente enzimática en ensayos posteriores. La concentración de proteína en el extracto enzimático fue determinada por el método de Lowry et al. (1951) usando como referencia albúmina de suero bovino (BSA) para generar la curva de calibración con un coeficiente de correlación de 0.9998 .

\section{Análisis de actividad enzimática de $A$. pullulans Determinación de la actividad de glucoamilasa}

Para determinar la actividad de glucoamilasa se preparó una mezcla de reacción que contenía $1 \mathrm{~mL}$ de una solución de $10 \mathrm{~g} / \mathrm{L}$ de almidón soluble en una solución amortiguadora de acetato, $0.2 \mathrm{~mol} / \mathrm{L}$, pH 4.5 y $0.1 \mathrm{~mL}$ de extracto enzimático. Se incubó a $60{ }^{\circ} \mathrm{C}$ por $30 \mathrm{~min}$, se centrifugó $7 \mathrm{~min}, 9240 \mathrm{~g}$ y $4{ }^{\circ} \mathrm{C}$. La concentración de glucosa se determinó en un analizador bioquímico (2700 Select, Yellow Springs Instruments) con base en el método de la glucosa oxidasa. Una unidad de actividad de glucoamilasa se definió como la cantidad de enzima requerida para liberar $1 \mu \mathrm{mol}$ de azúcares reductores (glucosa) por minuto en las condiciones de ensayo (Li et al. 2007a).

\section{Determinación de la actividad de a-amilasa}

El ensayo se realizó con una mezcla de reacción de $250 \mu \mathrm{L}$ de solución amortiguadora de acetato $0.2 \mathrm{~mol} / \mathrm{L}, \mathrm{pH} 4.5,250 \mu \mathrm{L}$ de $p$-nitrofenil- $\alpha$-Dmaltósido, $0.002 \mathrm{~mol} / \mathrm{L}\left(\right.$ Sigma Aldrich ${ }^{\circledR}$ ) y $50 \mu \mathrm{L}$ de extracto enzimático. Se incubó durante $30 \mathrm{~min}$ a $70{ }^{\circ} \mathrm{C}$; la reacción se detuvo adicionando $1 \mathrm{~mL}$ de carbonato de sodio $\left(\mathrm{Na}_{2} \mathrm{CO}_{3}\right) 2 \mathrm{~mol} / \mathrm{L}$ y el nitrofenol liberado se midió por absorción a $410 \mathrm{~nm}$. Una unidad $\alpha$-amilasa fue definida como la concentración de enzima que libera $1 \mu \mathrm{mol}$ de nitrofenol por minuto en la mezcla de reacción bajo las condiciones de ensayo (Silva et al. 2005).

\section{Determinación de la actividad a-glucosidasa}

Se realizó con una mezcla de reacción de 250 $\mu \mathrm{L}$ de solución amortiguadora de acetato $0.2 \mathrm{~mol} / \mathrm{L}$, $\mathrm{pH} 4.0,250 \mu \mathrm{L}$ de $p$-nitrofenil $\alpha$-D-glucopiranósido $0.005 \mathrm{~mol} / \mathrm{L}$ (Sigma Aldrich ${ }^{\circledR}$ ) y $50 \mu \mathrm{L}$ de extracto enzimático. Después de incubarse a $60^{\circ} \mathrm{C}$ por $30 \mathrm{~min}$, la reacción se detuvo adicionando $1 \mathrm{~mL}$ de $\mathrm{Na}_{2} \mathrm{CO}_{3}, 2$ $\mathrm{mol} / \mathrm{L}$ y el nitrofenol liberado se midió por absorción a $410 \mathrm{~nm}$. Una unidad $\alpha$-glucosidasa fue definida como la concentración de enzima que libera $1 \mu \mathrm{mol}$ de nitrofenol por minuto en la mezcla de reacción en las condiciones de ensayo (Saha et al. 1993).

\section{Determinación de la actividad $\beta$-glucosidasa}

Para determinar dicha actividad se preparó una mezcla de reacción de $250 \mu \mathrm{L}$ de solución amortiguadora de acetato $0.2 \mathrm{~mol} / \mathrm{L}, \mathrm{pH} 4.5,250 \mu 1 p$-nitrofenil$\beta$-D-glucopiranósido $0.004 \mathrm{~mol} / \mathrm{L}$ (Sigma Aldrich ${ }^{\circledR}$ ) y $50 \mu \mathrm{L}$ de extracto enzimático. Después de incubar a $60{ }^{\circ} \mathrm{C}$ por $30 \mathrm{~min}$, la reacción se detuvo adicionando $1 \mathrm{~mL}$ de $\mathrm{Na}_{2} \mathrm{CO}_{3}, 2 \mathrm{~mol} / \mathrm{L}$ y el color se midió a 410 $\mathrm{nm}$. Una unidad de $\beta$-glucosidasa fue definida como la concentración de enzima que libera $1 \mu \mathrm{mol}$ de nitrofenol por minuto en la mezcla de reacción en las condiciones de ensayo (Ribeiro et al. 2007).

\section{Ensayos de sacarificación de almidón}

Para evaluar la actividad de las enzimas amilolíticas producidas por $A$. pullulans, se realizaron ensayos de sacarificación usando almidón de cebada (AC) obtenido en este trabajo, almidón soluble (AS) de papa (S2004, Sigmal-Adrich ${ }^{\circledR}$ ) y almidón de maíz (AM) de la empresa Ingredion. La mezcla de reacción consistió en $1 \mathrm{~mL}$ de solución de almidón y $100 \mu \mathrm{L}$ de extracto enzimático con $0.84 \mathrm{mg} / \mathrm{mL}$ de proteína; se incubó a $60{ }^{\circ} \mathrm{C}$ durante $30 \mathrm{~min}$, agitándose a 200 rpm. Se centrifugó durante $10 \mathrm{~min}, 9240 \mathrm{~g} \mathrm{y} 4{ }^{\circ} \mathrm{C}$. El extracto enzimático liofilizado fue disuelto con una solución amortiguadora de acetato $0.2 \mathrm{~mol} / \mathrm{L}, \mathrm{pH}$ de 4.5 y agua destilada. En todas las etapas del experimento se determinó la concentración de glucosa mediante el analizador bioquímico. Se usó el programa estadístico Statgraphics Plus v. 4.0 y se estableció para todos los análisis la significancia $\mathrm{p}<0.05$. Se realizaron análisis de varianza y comparaciones de rangos múltiples (Fisher) para elegir las condiciones más adecuadas de hidrólisis. 
CUADRO I. RENDIMIENTOS OBTENIDOS EN LA ETAPA DE LIMPIEZA A PARTIR DE CEBADA

\begin{tabular}{ccccccc}
\hline $\begin{array}{c}\text { Peso inicial } \\
(\mathrm{kg})\end{array}$ & $\begin{array}{c}\text { Peso } \\
\text { grano } \\
(\mathrm{kg})\end{array}$ & $\begin{array}{c}\text { Rendimiento } \\
(\%)\end{array}$ & $\begin{array}{c}\text { Peso } \\
\text { grano } \\
(\mathrm{kg})\end{array}$ & $\begin{array}{c}\text { Peso } \\
\text { harina } \\
(\mathrm{kg})\end{array}$ & $\begin{array}{c}\text { Rendimiento } \\
(\%)\end{array}$ & $\begin{array}{c}\text { Rendimiento total } \\
(\%)\end{array}$ \\
\hline 2.5 & 2.08 & 83.2 & 2.08 & 2.06 & 99 & 84 \\
\hline
\end{tabular}

Los experimentos se realizaron de la siguiente manera: en la primera etapa se usó una concentración de $10 \mathrm{~g} / \mathrm{L}$ para los tres almidones aplicando tres tratamientos. En el primero se usó como disolvente un amortiguador de acetato $0.2 \mathrm{~mol} / \mathrm{L}, \mathrm{pH} 4.5$, debido a que se han reportado amilasas que tienen mayor actividad enzimática en un rango de $\mathrm{pH}$ ácido. En el segundo se usó agua destilada desionizada, $\mathrm{pH}$ 7.0, para comparar la actividad a $\mathrm{pH}$ no controlado y porque esta condición se usa a nivel industrial durante el proceso de sacarificación de almidón (Bentley 1999). En el tercer tratamiento, usando ambos disolventes, se determinó el efecto del ion $\mathrm{Ca}^{2+}$ al adicionar $\mathrm{Ca}_{2} \mathrm{Cl}_{2}(0.1 \mathrm{~mol} / \mathrm{L})$, del cual se ha reportado que tiene un rol importante en la estabilidad estructural y, por lo tanto, en la actividad enzimática de muchas amilasas (Ghollasi et al. 2013). Una vez seleccionadas las mejores condiciones de hidrólisis con una concentración de $10 \mathrm{~g} / \mathrm{L}$ de almidón, en la segunda etapa se aplicó un proceso de gelatinización para favorecerla, incubando el almidón a $100{ }^{\circ} \mathrm{C}$ durante $90 \mathrm{~min}$, con agitación a $200 \mathrm{rpm}$. Posteriormente se desarrolló la reacción de hidrólisis, y se comparó la concentración de glucosa obtenida al usar almidón gelatinizado y sin gelatinizar (Bentley 1999, Konsula et al. 2004). En la tercera etapa se aumentó la concentración de almidón a 50, 100, 200 y $400 \mathrm{~g} / \mathrm{L}$, incubando a $30 \mathrm{~min}$ y $24 \mathrm{~h}$, en las condiciones ya mencionadas, para determinar si aumenta la concentración de glucosa producida; se ha reportado que es posible gelatinizar una solución de almidón con 30-40 \% de sólidos para posteriormente realizar la licuefacción (Bentley 1999).

\section{Análisis de los productos de hidrólisis por croma- tografía en capa fina}

Los productos de sacarificación del almidón fueron analizados por cromatografía en capa fina (TLC, por sus siglas en inglés). Las mezclas de reacción de los diferentes experimentos de sacarificación se centrifugaron $10 \mathrm{~min}$, a $9240 \mathrm{~g} \mathrm{y} 4{ }^{\circ} \mathrm{C}$. Posteriormente, $1 \mu \mathrm{L}$ de cada muestra se depositó en una placa de sílice $60 \mathrm{~F}_{254}$ (Merck). Se utilizó como testigo el almidón sin enzima correspondiente en cada caso (AC, AS y AM). El sistema de elución se preparó con butanol-etanol-agua-ácido acético (4:4:2:0.5 $\mathrm{v} / \mathrm{v} / \mathrm{v} / \mathrm{v}$ ), y se utilizó glucosa como estándar. Los productos fueron revelados rociando la placa con ácido sulfúrico en metanol al $10 \%(\mathrm{v} / \mathrm{v})$ y calentando a $100{ }^{\circ} \mathrm{C}$ en un horno hasta la aparición de manchas de revelado ("spots" en inglés) de color café que indican la presencia de glucosa (Sarian et al. 2012).

\section{RESULTADOS Y DISCUSIÓN}

\section{Aislamiento de almidón a partir de granos de cebada}

Para obtener el almidón a partir de los granos de cebada, se realizó una extracción por molienda húmeda que implica la obtención de una suspensión (de color blanco) durante los lavados. La suspensión de almidón centrifugada presentó dos fases: café en la parte superior y blanca en la parte inferior. La fase café se debe al contenido de proteínas, fibra y gluten, mientras que la fase blanca corresponde al almidón (Vasanthan y Hoover 2009). Estas dos fases se forman debido a la diferencia de densidades de gluten hidratado $(1.1 \mathrm{~g} / \mathrm{mL})$ en comparación con el almidón $(1.5 \mathrm{~g} / \mathrm{mL})$, lo que facilita su separación al formar una pastilla. Los rendimientos de la etapa de limpieza y de extracción del almidón se presentan en los cuadros I y II, respectivamente. El rendimiento de $29 \%$ de almidón del presente estudio es comparable al reportado por Quintos et al. (2009), quienes obtuvieron 35.9 y $30.2 \%$ a partir de la cebada variedad Esmeralda Apan perlada y sin perlar,

CUADRO II. RENDIMIENTO DE ALMIDÓN OBTENIDO EN LA FASE DE EXTRACCIÓN A PARTIR DE CEBADA

\begin{tabular}{cccc}
\hline $\begin{array}{c}\text { Peso harina } \\
(\mathrm{kg})\end{array}$ & $\begin{array}{c}\text { Peso } \\
\text { almidón } \\
(\mathrm{kg})\end{array}$ & $\begin{array}{c}\text { Peso } \\
\text { pigmentos } \\
(\mathrm{kg})\end{array}$ & $\begin{array}{c}\text { Rendimiento } \\
\text { de almidón } \\
(\%)\end{array}$ \\
\hline 2.08 & 0.6 & 0.598 & 29 \\
\hline
\end{tabular}


respectivamente, y de la variedad Esmeralda Almoloya $33.8 \%$ perlada y $28.4 \%$ sin perlar. Por otro lado, se considera moderado respecto a Prieto et al. (2009), quienes reportaron $60 \%$ de rendimiento con cebada de buena calidad, utilizando cloruro de mercurio para favorecer la separación. Estos resultados indican que al tratarse de cebada de baja calidad podría ser materia prima potencial para obtener otros productos de interés.

\section{Evaluación del crecimiento de $A$. pullulans a nivel matraz}

Las cinéticas de crecimiento de A. pullulans se desarrollaron en cultivos a nivel matraz en medio líquido ajustado a tres diferentes relaciones $\mathrm{C}: \mathrm{N}$, con el objetivo de generar biomasa. En la figura 1 se observa el comportamiento cinético de A. pullulans para las relaciones C:N 20, 15 y 8 . A las $12 \mathrm{~h}$ la densidad celular (células $/ \mathrm{mL}$ ) fue de $5.37 \times 10^{8}$, $1.55 \times 10^{9}$ y $1.87 \times 10^{9}$ respectivamente. Se observó que posteriormente el crecimiento celular disminuye. Generalmente cuando se requiere propagar un cultivo a nivel reactor se debe de escoger la condición en que se obtenga un mejor crecimiento (cuentas celulares) en un tiempo adecuado. En las condiciones analizadas, la relación $\mathrm{C}: \mathrm{N} 8$ a las 12 h cubre esta característica y es la que se utilizó para el cultivo en reactor; se obtuvo con una concentración de 50 $\mathrm{g} / \mathrm{L}$ de almidón de cebada y $8.6 \mathrm{~g} / \mathrm{L}$ de $\mathrm{NH}_{4} \mathrm{Cl}$. Las relaciones de $\mathrm{C}: \mathrm{N} 15$ y 20 presentaron un 15 y $71 \%$ menor cantidad de células a las $12 \mathrm{~h}$.

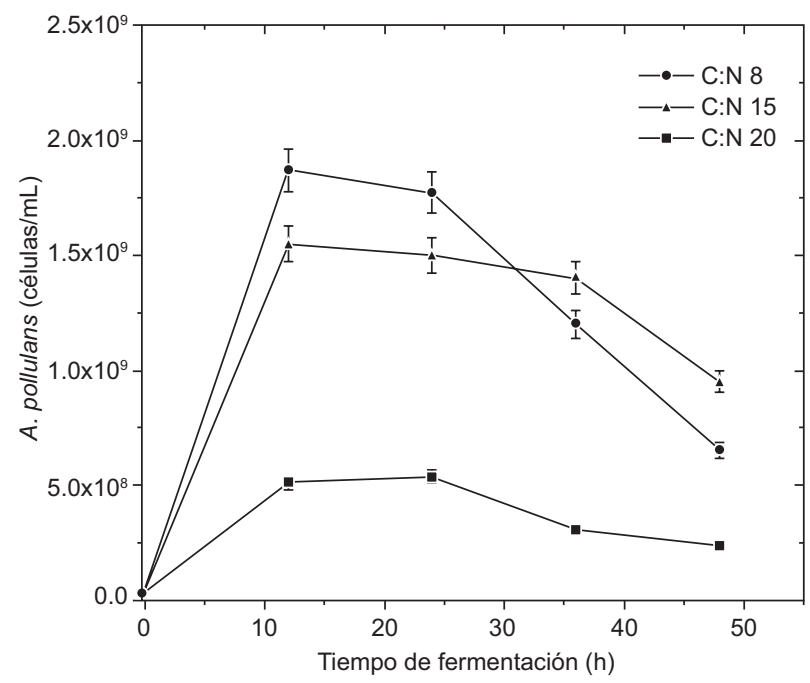

Fig. 1. Crecimiento de Aureobasidium pullulans en matraz a $\mathrm{C}: \mathrm{N}$ de 8,15 y 20

\section{Cultivo a nivel reactor de $A$. pullulans}

La figura 2 muestra la cinética de crecimiento a nivel reactor, así como las diferentes actividades enzimáticas: glucoamilasa, $\alpha$-amilasa, $\alpha$-glucosidasa y $\beta$-glucosidasa. En el cuadro III se presentan las actividades máximas alcanzadas en la fermentación. Al tratarse de enzimas inducibles, se observó que su producción inicia desde las primeras horas de la fermentación. Se aprecia una actividad importante glucoamilasa después de las $10 \mathrm{~h}$, que se incrementa conforme avanza el tiempo de fermentación, mostrando la máxima actividad a las $15 \mathrm{~h}$ con $193 \mathrm{U} / \mathrm{mL}$. Li et al. (2007b) evaluaron A. pullulans N-13d con almidón soluble $(10 \mathrm{~g} / \mathrm{L})$ y reportaron una actividad máxima de $10 \mathrm{U} / \mathrm{mL}$ a las $32 \mathrm{~h}$, la cual se mantuvo constante hasta las $72 \mathrm{~h}$. Goyal et al. (2005) reportan con Bacillus sp. I-3 actividades de glucoamilasa de 90 y $181 \mathrm{U} / \mathrm{mL}$ usando almidón soluble y almidón de maíz, respectivamente, mientras que con amilosa y amilopectina determinaron 0.34 y $0.47 \mathrm{U} / \mathrm{mL}$, respectivamente.

En cuanto a la producción de glucosidasas, la figura 2 muestra que la producción de $\alpha$-glucosidasa coincide con el crecimiento de $A$. pullulans. La máxima producción fue de las 24 a las $30 \mathrm{~h}$ (valor promedio de $8.1 \mathrm{U} / \mathrm{mL}$ ), lo cual coincide con la fase estacionaria. Hasta la fecha sólo en el trabajo de Saha et al. (1993) se reporta la producción de una $\alpha$-glucosidasa por A. pullulans NRRL Y12974. Estos investigadores obtuvieron actividades de $2.14,0.77 \mathrm{y}$ $1.59 \mathrm{U} / \mathrm{mL}$ en almidón, amilosa y amilopectina, respectivamente, todos a una concentración de $10 \mathrm{~g} / \mathrm{L}$.

La producción de $\beta$-glucosidasa coincidió con el crecimiento y mostró su actividad máxima a las $24 \mathrm{~h}$ con $8.5 \mathrm{U} / \mathrm{mL}$ (figura 2). Este valor es mayor que el reportado por Saha et al. (1993), quienes obtuvieron una actividad de $0.27 \mathrm{U} / \mathrm{mL}$ al evaluar $A$. pullulans NRRL Y12974 con salvado de maíz como sustrato a $10 \mathrm{~g} / \mathrm{L}$. Ribeiro et al. (2008) evaluaron $A$. pullulans ER-16 usando salvado de trigo a $10 \mathrm{~g} / \mathrm{L}$, obtuvieron una actividad de $1.3 \mathrm{U} / \mathrm{mL}$. Respecto a la producción y actividad de $\alpha$-amilasa, en la misma figura se observa que a las $30 \mathrm{~h}$ presentó su mayor actividad con $7.4 \mathrm{U} / \mathrm{mL}$, mostrando un perfil similar a las glucosidasas. Sólo Saha y Bothast (1993) reportaron haber obtenido una producción de $\alpha$-amilasa por $A$. pullulans NRRLY12794 con $0.47 \mathrm{U} / \mathrm{mL}$ de actividad, en fermentación en sustrato sólido y cuatro días de proceso.

Por lo anterior, la producción de enzimas amilolíticas por A. pullulans ATCC15233 al usar almidón de cebada de baja calidad como sustrato es adecuada, debido a que la actividad de estas enzimas fue 


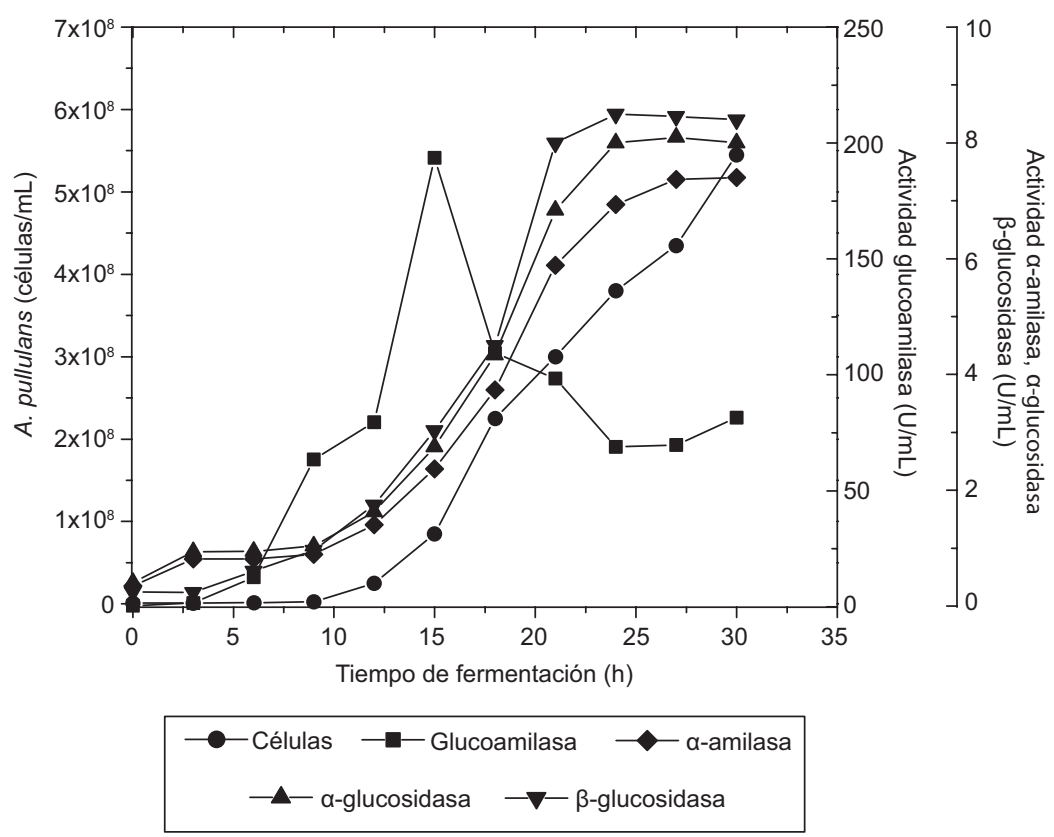

Fig. 2. Cinética de crecimiento de Aureobasidium pullulans ATCC15233 y actividad enzimática de glucoamilasa, $\alpha$-glucosidasa, $\beta$-glucosidasa y $\alpha$-amilasa en cultivos en lote a nivel reactor

CUADRO III. ACTIVIDADES MÁXIMAS DE ENZIMAS AMILOLÍTICAS PRODUCIDAS POR Aureobasidium pullulans

\begin{tabular}{lcc}
\hline Enzimas & $\begin{array}{c}\text { Actividad } \\
\text { enzimática } \\
(\mathrm{U} / \mathrm{mL})\end{array}$ & $\begin{array}{c}\text { Tiempo de } \\
\text { fermentación }(\mathrm{h})\end{array}$ \\
\hline Glucoamilasa & 193 & 15 \\
$\alpha$-glucosidasa & 8.1 & $24-30$ \\
$\beta$-glucosidasa & 8.5 & 24 \\
$\alpha$-amilasa & 7.4 & 30 \\
\hline
\end{tabular}

superior a la que se ha reportado hasta el momento para dicha levadura. Cabe mencionar que la comparación se hace con diferentes cepas. Esto sugiere que el almidón de cebada de baja calidad puede ser utilizado como sustrato potencial para la producción de productos de valor agregado como las enzimas.

\section{Sacarificación enzimática de almidones de maíz, soluble y de cebada}

En la primera etapa se usaron dos medios de reacción, un amortiguador de acetato $0.2 \mathrm{~mol} / \mathrm{L}$ y agua destilada sin la adición de $\mathrm{Ca}^{2+}$ y con la adición de $\mathrm{Ca}^{2+}$ en la mezcla de reacción (Fig. 3a). Para el almidón de cebada (AC), la sacarificación fue aparentemente mejor con el amortiguador de acetato (efecto significativo, $\mathrm{p}<0.05$ ) y en presencia de $\mathrm{Ca}^{2+}$, siendo la concentración máxima de glucosa obtenida de $3.84 \mathrm{~g} / \mathrm{L}$. Para el caso del almidón soluble (AS) fue mejor la condición de agua destilada $\mathrm{Ca}^{2+}$, obteniéndose $0.84 \mathrm{~g} / \mathrm{L}$ de glucosa. Respecto a el almidón de maíz (AM), se determinó diferencia significativa $(\mathrm{p}<0.05)$ entre los cuatro tratamientos, obteniéndose la máxima concentración de glucosa de $0.4 \mathrm{~g} / \mathrm{L}$ al usar agua y $\mathrm{Ca}^{2+}$. En la figura $3 \mathbf{b}$ se presenta el análisis de TLC, donde se demuestra que el producto de reacción mayoritario fue glucosa para cada fuente de almidón. Konsula et al. 2004 reportaron una $\alpha$-amilasa producida por Bacillus subtilis que aumentó su actividad relativa de 84.6 a $96 \%$ en presencia de $\mathrm{Ca}^{2+}(0.8 \mathrm{~mol} / \mathrm{L})$ a $60^{\circ} \mathrm{C}$. En el presente trabajo la combinación del amortiguador de acetato con $\mathrm{Ca}^{2+}$ fue estadísticamente mejor. Sin embargo, se decidió usar agua y $\mathrm{Ca}^{2+}$ como medio de reacción en los siguientes experimentos debido a que el agua es utilizada a nivel industrial durante el proceso de sacarificación de almidón (Bentley 1999).

En la segunda etapa se utilizó la suspensión de almidón gelatinizado y sin gelatinizar a $10 \mathrm{~g} / \mathrm{L}$ (Fig. 4a). Se observa que, para almidón de cebada, el almidón gelatinizado no favorece el porcentaje de hidrólisis y se determinó que no hay diferencia significativa; se obtuvieron 3.2 y $3.1 \mathrm{~g} / \mathrm{L}$ de glucosa para almidón gelatinizado y sin gelatinizar, 

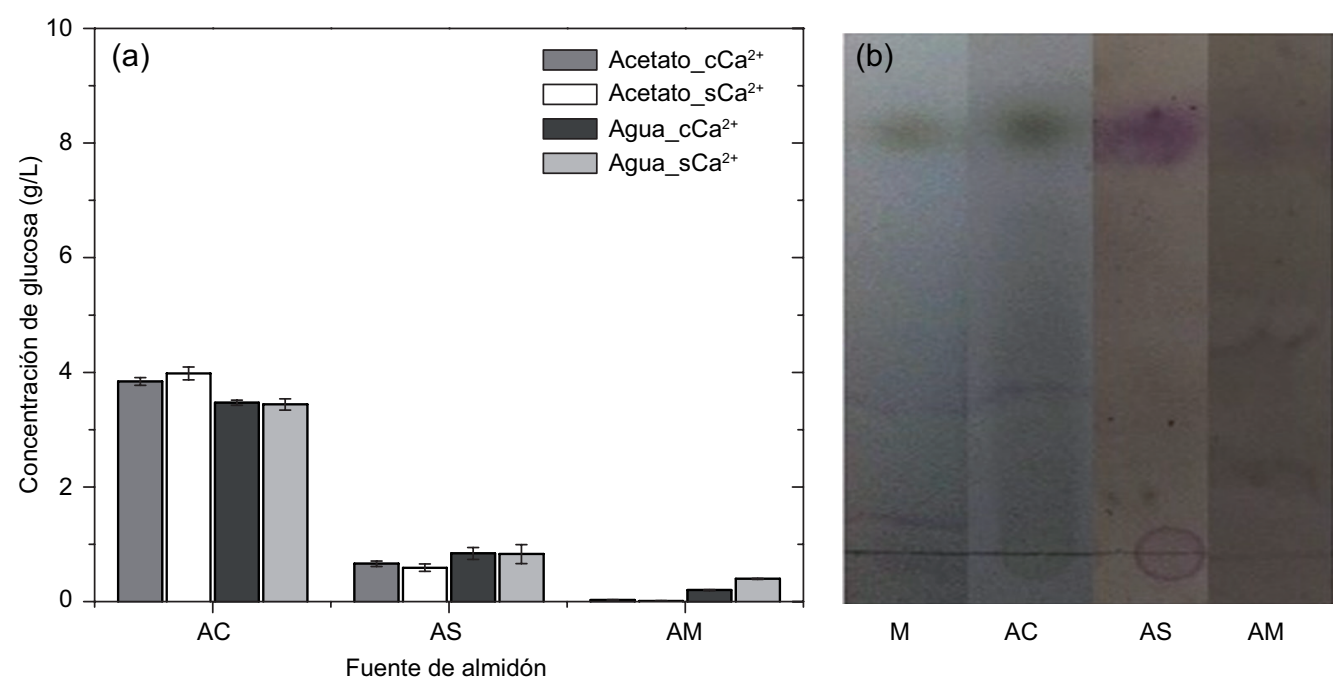

Fig. 3. Hidrólisis enzimática de almidón de diferentes fuentes $(10 \mathrm{~g} / \mathrm{L})$. (a) Almidón de cebada (AC), almidón soluble (AS) y almidón de maíz (AM), con agua y amortiguador de acetato ( $\mathrm{pH} 4.5$ ), con y sin adición de $\mathrm{Ca}^{2+}$. (b) Análisis de los productos por cromatografía en capa fina. M: marcador (glucosa)
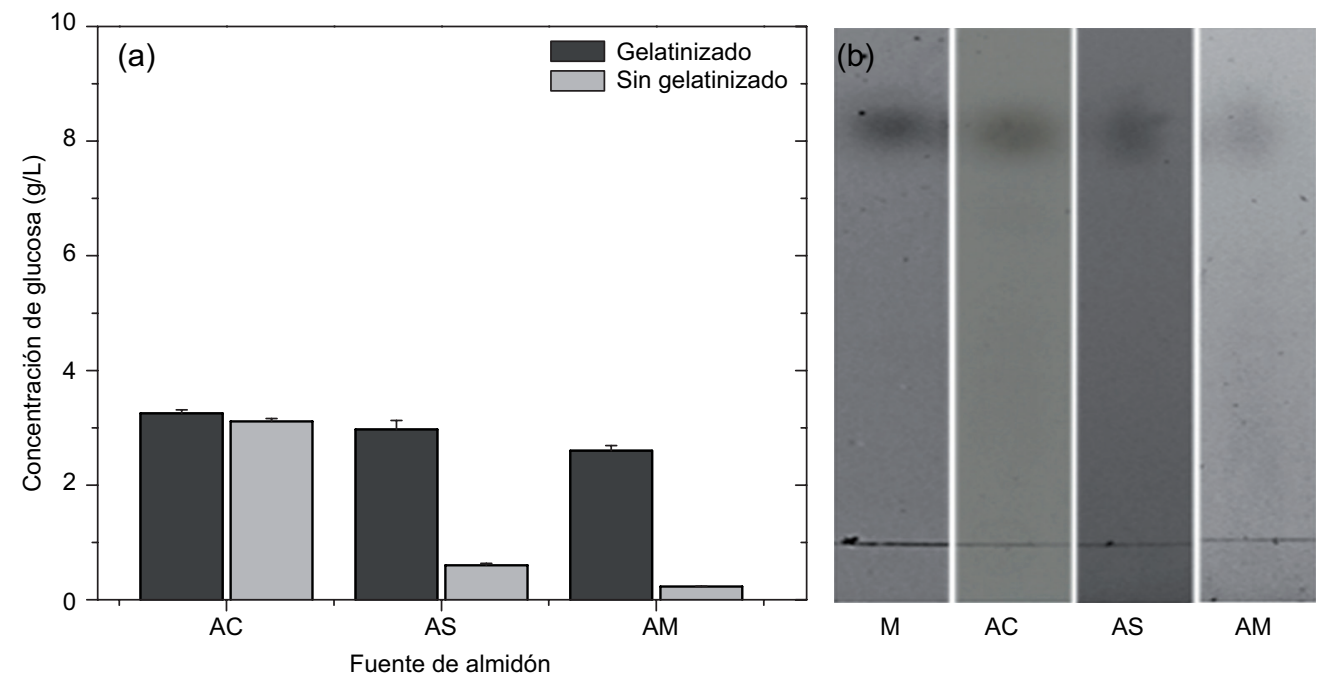

Fig. 4. Hidrólisis enzimática de almidón de diferentes fuentes $(10 \mathrm{~g} / \mathrm{L})$. (a) Almidón de cebada (AC), almidón soluble (AS) y almidón de maíz (AM), en un sistema acuoso, usando almidón gelatinizado y sin gelatinizar, con adición de $\mathrm{Ca}^{2+}$. (b) Análisis de los productos por cromatografía en capa fina. M: marcador (glucosa)

respectivamente. En la figura $4 \mathbf{b}$ se corrobora que la glucosa es el producto principal de la hidrólisis. Respecto al almidón soluble, se produjeron 2.9 y 0.6 $\mathrm{g} / \mathrm{L}$ de glucosa usando almidón gelatinizado y sin gelatinizar, respectivamente, lo cual representa una hidrólisis mayor con una diferencia significativa $(\mathrm{p}$ $<0.05$ ) al gelatinizar el almidón soluble.

Finalmente, para el almidón de maíz se produjeron 2.6 y $0.23 \mathrm{~g} / \mathrm{L}$ a partir de almidón gelatinizado y sin gelatinizar, respectivamente.
Estos resultados indican que el tratamiento de gelatinización favoreció la hidrólisis de AS y AM, incrementado la susceptibilidad a la degradación enzimática en comparación con sus formas nativas, es decir, sin gelatinizar, lo cual es congruente con reportes previos (O'Brien y Wang 2008). Por ejemplo, al gelatinizar almidón de papa y arroz, se aumentó la concentración de azúcares reductores liberados de 17 a $29 \mathrm{mg} / \mathrm{mL}$ y de 14 a $24 \mathrm{mg} / \mathrm{mL}$, respectivamente (Konsula et al. 2004). 
En la tercera etapa se aumentó la concentración de los diferentes almidones a 50, 100, 200 y $400 \mathrm{~g} / \mathrm{L}$, al adicionar $\mathrm{Ca}^{2+}$ con un proceso de gelatinizado (Fig. 5). Los resultados demuestran que, para almidón de cebada, la mejor condición se obtuvo a 30 min de reacción y $50 \mathrm{~g} / \mathrm{L}$ con $8.7 \%$ de hidrólisis, siendo menor con $100 \mathrm{~g} / \mathrm{L}(6.5 \%), 200 \mathrm{~g} / \mathrm{L}(6.7 \%)$ y $400 \mathrm{~g} / \mathrm{L}(5.98 \%)$. Al evaluarse el tiempo de reacción de $24 \mathrm{~h}$ se determinó que éste no favorece la hidrólisis de manera importante, ya que se registraron aumentos únicamente de $3.2,1.62,0.42$ y $0.26 \%$ para 50 , 100,200 y 400 g/L, respectivamente (Fig. 5b). Para almidón soluble a $30 \mathrm{~min}$ de reacción y $50 \mathrm{~g} / \mathrm{L}$ se obtuvo $7.32 \%$ de hidrólisis; conforme se aumentó la concentración la hidrólisis disminuyó, obteniéndose los siguientes porcentajes de hidrólisis: $4.09 \%$ $(100 \mathrm{~g} / \mathrm{L}), 2.46 \%$ (200 g/L) y $1.89 \%(400 \mathrm{~g} / \mathrm{L})$ (Fig. 5a). Sin embargo, cuando el tiempo de reacción fue de $24 \mathrm{~h}$, la hidrólisis se incrementó en 47.9, 27.9, 13.9 y $7.0 \%$ para $50,100,200$ y $400 \mathrm{~g} / \mathrm{L}$, respectivamente (Fig. 5b).

Con relación al almidón de maíz, a 30 min de reacción se obtuvieron los siguientes porcentajes de hidrólisis: $6.0,3.7,3.4$ y $1.9 \%$ con $50,100,200$ y $400 \mathrm{~g} / \mathrm{L}$, respectivamente (Fig. 5a). A las $24 \mathrm{~h}$ la hidrólisis tuvo un efecto significativo positivo, aumentando $42,21.7,12.4$ y $6.0 \%$ para $50,100,200$ y 400 g/L, respectivamente (Fig. 5b). El gránulo de almidón de maíz presenta una estructura más compleja en comparación con el almidón de cebada y el almidón soluble proveniente de papa (Naguleswaran et al. 2013), por lo que se requiere de mayor tiempo de reacción para favorecer la hidrolisis, como se observó en este ensayo. El análisis por TLC indicó que la glucosa es el producto principal de la hidrólisis (Fig. 6).

En general, para los tres almidones la hidrólisis aumentó cuando se incrementó de 10 a $50 \mathrm{~g} / \mathrm{L}$; sin embargo, para concentraciones superiores a $100 \mathrm{~g} / \mathrm{L}$ no se observó algún efecto, lo que sugiere que la viscosidad es más alta al aumentar la concentración del almidón gelatinizado, ocasionando que la velocidad de agitación sea insuficiente para favorecer el mezclado y la interacción entre la enzima y el sustrato. Además, es posible que se haya producido inhibición por sustrato. Observaciones similares se reportaron para almidón de yuca (Ruiz et al. 2011). Cabe mencionar que la hidrólisis entre los almidones depende principalmente de sus diferencias estructurales (relación amilosa-amilopectina), que los hacen más o menos susceptibles a las enzimas (Naguleswaran et al. 2012).

Las enzimas amilolíticas producidas por $A$. pullulans presentan ventajas debido a que hidrolizan almidón a $60{ }^{\circ} \mathrm{C}$, temperatura menor a las reportadas en procesos de sacarificación $\left(90^{\circ} \mathrm{C}\right)$ (Bentley 1999), además de que se obtiene glucosa como principal producto de reacción. Más aún, al ser un extracto crudo (es decir, sin que se aplique algún método de purificación) la sacarificación se puede realizar en una etapa, en comparación con los procesos industriales. En éstos, después de las etapas de gelatinización y licuefacción del almidón, la sacarificación se realiza en dos fases con enzimas purificadas y en secuencia:
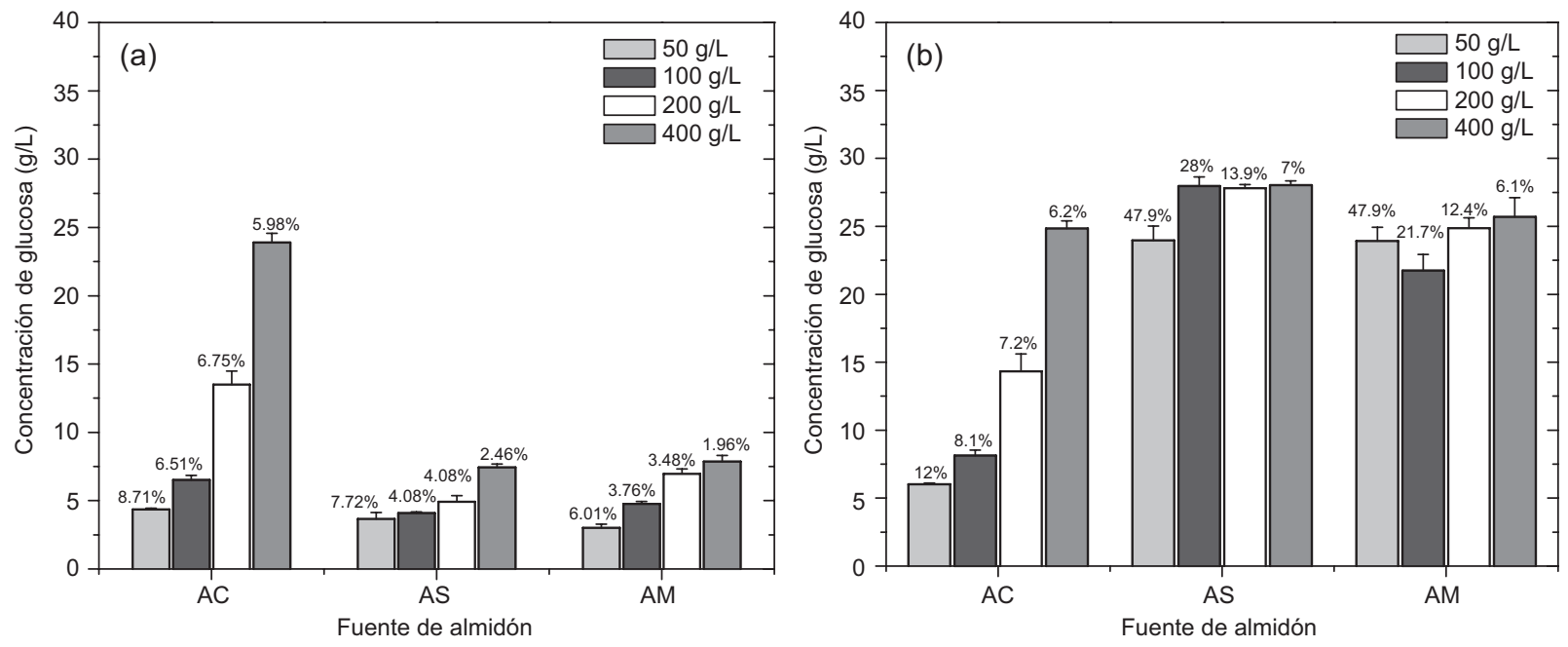

Fig. 5. Hidrólisis enzimática de almidón: almidón de cebada (AC), almidón soluble (AS) y almidón de maíz (AM), en un sistema acuoso, usando almidón gelatinizado en diferentes concentraciones, con $\mathrm{Ca}^{2+}$. La reacción se realizó durante (a) $30 \mathrm{~min}$ y (b) $24 \mathrm{~h}$. Se indican los porcentajes de hidrólisis para cada fuente de almidón 

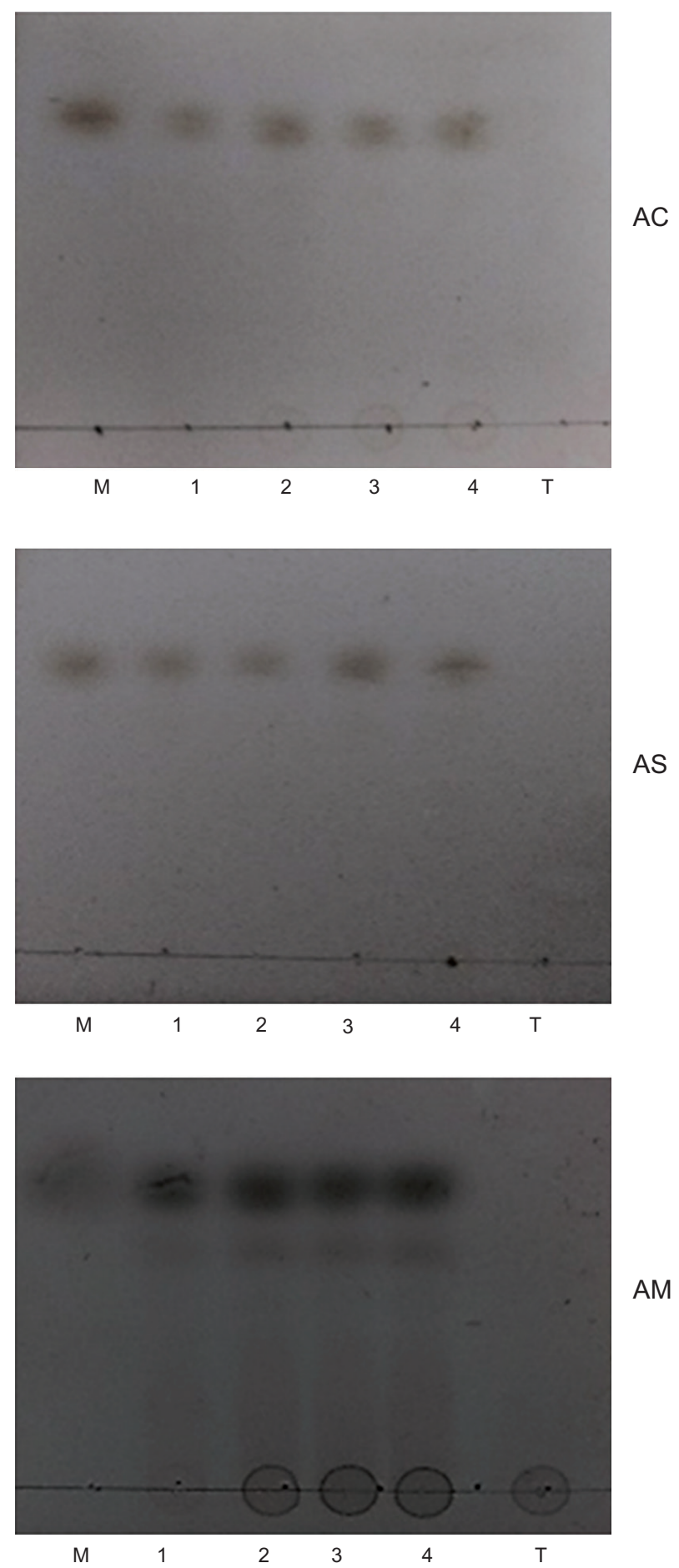

Fig. 6. Análisis de los productos de hidrólisis por cromatografía en capa fina: almidón de cebada (AC), almidón soluble de papa (AS) y almidón de maíz (AM), a 24 h en diferentes concentraciones. M: marcador (glucosa) (1:50, 2:100, 3:200 y 4:400 g/L); T: testigo primero una $\alpha$-amilasa (primera fase, con dextrinas y oligómeros como principales productos de reacción) y posteriormente glucoamilasas (segunda fase, con glucosa como principal producto de reacción) (van der Maarel et al. 2002). Por ello el uso de extractos de amilasas de $A$. pullulans podría disminuir el tiempo y costo de los procesos de sacarificación.

\section{CONCLUSIONES}

Con base en los resultados anteriores, las cosechas de cultivos como cebada que no cumplan con los requisitos para la alimentación del ganado y la industria alimentaria, pueden considerarse como materia prima de bajo costo para la obtención de productos de valor agregado como enzimas amilolíticas. En el presente trabajo el almidón de cebada de baja calidad fue aprovechado como materia prima para la producción de enzimas amilolíticas por A. pullulans (glucoamilasa, $\alpha$-glucosidasa, $\beta$-glucosidasa y $\alpha$-amilasa) y mostraron capacidad para hidrolizar almidón de cebada, almidón soluble y almidón de maíz en condiciones que se aplican en procesos industriales de sacarificación.

\section{AGRADECIMIENTOS}

Agradecemos el apoyo técnico de José Alejandro Santiago Hernández del Departamento de Biotecnología y Bioingeniería del Centro de Investigación y de Estudios Avanzados del Instituto Politécnico Nacional (CINVESTAV-IPN), así como el apoyo de los proyectos de la Secretaría de Investigación y Posgrado: 20151569 y 201609 . Asimismo, los apoyos de la Comisión de Operación y Fomento de Actividades Académicas (COFAA-IPN) y las becas de estímulo institucional de formación de investigadores (BEIFI) para María Isabel Hernández Castillo y del Consejo Nacional de Ciencia y Tecnología (CONACYT) (núm. de becario 246766).

\section{REFERENCIAS}

Aguilar J. y Schwentesius R. (2004). La producción de cebada maltera en México, ventaja comparativa no capitalizada. Reporte de investigación. Centro de Investigaciones Económicas, Sociales y Tecnológicas de la Agroindustria y la Agricultura Mundial (CIESTAAM), Universidad Autónoma Chapingo, Estado de México, México, 61 pp. 
Bello L.A., Sánchez M.M., Núñez C., Rodríguez S.L. y Román A.D. (2010). Effect of the pearled in the isolation and the morphological, physicochemical and rheological characteristics of barley starch. Carbohy. Polym. 81, 63-69.

DOI: 10.1016/j.carbpol.2010.01.056

Bentley I.S. (1999). Enzymes, starch conversion. En: The encyclopedia of bioprocess technology: fermentation, biocatalysis, and bioseparation (Flickinger M.C. y Drew S.W., Eds.). John Wiley and Sons, Nueva York, EUA, pp. 1104-1112.

Botella C., Ory I., Webb C., Cantero D. y Blandino A. (2005). Hydrolytic enzyme production by Aspergillus awamori on grape pomace. Biochem. Eng. J. 26, 100106. DOI: $10.1016 / j . b e j .2005 .04 .020$

Castilho L.R., Medronho R.A. y Alves T.L.M. (2000). Production and extraction of pectinases obtained by solid state fermentation of agroindustrial residues with Aspergillus niger. Biores. Technol. 71 (1), 45-50. DOI: 10.1016/S0960-8524(99)00058-9

Demirkan E.S., Mikami B., Adachi M., Higasa T. y Utsumi S. (2005). $\alpha$-Amylase from B. amyloliquefaciens: purification, characterization, raw starch degradation and expression in E. coli. Process Biochem. 40, 26292636. DOI: $10.1016 /$ j.procbio.2004.08.015

Dinorín J., Delgado R., Larralde P., Martínez F., de la Torre M. y López V.E. (2015). Reactance and resistance: Main properties to follow the cell differentiation process in Bacillus thuringiensis by dielectric spectroscopy in real time. Appl. Microbiol. Biotechnol. 99, 5439-5450. DOI: 10.1007/s00253-015-6562-9

Djekrif D.S., Gillmann L., Bennamoun L., Ait-Kaki A., Labbani K., Nouadri T. y Meraihi Z. (2015). Amylolytic yeasts: Producers of $\alpha$-amylase and pullulanase. Int. J. Life. Sci. Scienti. Res. 2 (4), 339-354.

DOI: 10.21276/ijlssr.2016.2.4.6

FAO (2018). FAOSTAT. Producción, cultivos. Organización de las Naciones Unidas para la Alimentación y la Agricultura [en línea]. http://www.fao.org/faostat/ es/\#data/QC 02/07/2018

Ghollasi M., Ghanbari M. y Khajeh K. (2013). Improvement of thermal stability of a mutagenised $\alpha$-amylase by manipulation of the calcium-binding site. Enzyme Microb. Technol. 53, 406-413. DOI: $10.1016 /$ j.enzmictec.2013.09.001

Godoy M.G., Gutarra M.L.E., Maciel F.M., Felix S.P., Bevilaqua J.V., Machado O.L.T. y Freire D.M.G. (2009). Use of a low-cost methodology for biodetoxification of castor bean waste and lipase production. Enzyme Microb. Technol. 44 (5), 317-322. DOI: $10.1016 /$ j.enzmictec.2009.01.002

Goyal N., Gupta K.J. y Soni K.S. (2005). A novel raw digesting thermostable $\alpha$-amylase from Bacillus sp.
I-3 and its use in the direct hydrolysis of raw potato starch. Enzyme Microb. Technol. 37, 723-734.

DOI: 10.1016/j.enzmictec.2005.04.017

Gupta R., Gigras P., Mohapatra H., Goswami V.K. y Chauhan B. (2003). Microbial $\alpha$-amylases: Biotechnological perspective. Process Biochem. 38, 1599-1616.

DOI: 10.1016/S0032-9592(03)00053-0

Hayashi S., Sako S., Yokoi H., Takasaki Y. e Imada K. (1999). Purification and characterization of the intracellular $\beta$-glucosidase from Aureobasidium sp. ATCC 20524. J. Ind. Microb. Biotechnol. 22, 160-163.

DOI: $10.1038 /$ sj.jim. 2900618

Konsula Z. y Liakopoulou-Kyriakides M. (2004). Hydrolysis of starches by the action of an $\alpha$-amylase from Bacillus subtilis. Process Biochem. 39, 1745-1749. DOI: 10.1016/j.procbio.2003.07.003

Li H., Chi Z., Duan X., Wang L., Sheng J. y Wu L. (2007a). Glucoamylase production by the marine yeast Aureobasidium pullulans N13d and hydrolysis of potato starch granules by the enzyme. Process Biochem. 42, 462-465.

DOI: 10.1016/j.procbio.2006.09.012

Li H., Chi Z., Wang X., Duan X., Ma L. y Gao L. (2007b). Purification and characterization of extracellular amylase from the marine yeast Aureobasidium pullulans $\mathrm{N} 13 \mathrm{~d}$ and its raw potato starch digestion. Enzyme Microb. Technol. 40, 1006-1012.

DOI: $10.1016 / j$.enzmictec.2006.07.036

Lowry O.H., Rosebrough N.J., Farr A.L. y Randall R.J. (1951.) Protein measurement with the Folin phenol reagent. J. Biol. Chem. 1 (93), 267-275.

Naguleswaran S., Li J., Vasanthan T., Bressler D. y Hoover R. (2012). Amylolysis of large and small granules of native triticale, wheat and corn starches using a mixture of $\alpha$-amylase and glucoamylase. Carbohy. Polym. (88), 864-874.

DOI: 10.1016/j.carbpol.2012.01.027

Naguleswaran S., Vasanthan T., Hoover R. y Bressler D. (2013). The susceptibility of large and small granules of waxy, normal and high-amylose genotypes of barley and corn starches toward amylolysis at sub-gelatinization temperatures. Food Res. Int. 51, 771-782.

DOI: 10.1016/j.foodres.2013.01.057

O'Brien S. y Wang Y.J. (2008). Susceptibility of annealed starches to hydrolysis by $\alpha$-amylase and glucoamylase. Carbohy. Polym. 72, 597-607.

DOI: 10.1016/j.carbpol.2007.09.032

Oliveira L.A., Porto A.L.F. y Tambourgi E.B. (2006). Production of xylanase and protease by Penicillium janthinellum CRC 87M-115 from different agricultural wastes. Biores. Technol. 97 (6), 862-867.

DOI: 10.1016/j.biortech.2005.04.017 
Prieto M.J., Rubio H.C.U., Román G.A.D., Méndez M.M.A., González R.C.A. y Prieto G.F. (2009). Degradación física del almidón de cebada (Hordeum sativum Jess). Correlación entre la gelatinización y el tamaño de gránulos. Multiciencias 9 (2), 115-125.

Quintos J., Delgadillo M., Prieto F. y Román A.D. (2009). Aislamiento y caracterización de almidón de cebada (Hordeum vulgare) de la variedad esmeralda de los municipios de Apan y Almoloya Hidalgo. Memorias. XI Congreso Nacional de Ciencia y Tecnología de alimentos. Monterrey, Nuevo León. 31 de agosto y 1 de septiembre (CD-ROM).

Rana N., Walia A. y Gaur A. (2013). $\alpha$-Amylases from microbial sources and its potential applications in various industries. Natl. Acad. Sci. Lett. 36 (1), 9-17. DOI: 10.1007/s40009-012-0104-0

Ribeiro L.R.S., Ferreira A.P.H., Cabral H., Pagnocca F.C., Gomes E. y da Silva R. (2008). Production and characteristics comparison of crude $\beta$-glucosidases produced by microorganisms Thermoascus aurantiacus e Aureobasidium pullulans in agricultural wastes. Enzyme Microb. Technol. 43, 391-395. DOI: 10.1016/j.enzmictec.2008.07.006

Ruiz M.I., Sánchez C.I., Torrres R.G. y Molina D.R. (2011). Enzymatic hydrolysis of cassava starch for production of bioethanol with a Colombian wild yeast strain. J. Braz. Chem. Soc. 22 (12), 2337-2343.

DOI: $10.1590 / \mathrm{S} 0103-50532011001200014$

Saha B.C., Silman W.R. y Bothast J.R. (1993). Amylolytic enzymes produced by a color variant strain of Aureobasidium pullulans. Curr. Microbiol. 26, 267-273. DOI: 10.1007/BF01575916

Saha B.C. y Bothast R.J. (1993). Starch conversion by amylases from Aureobasidium pullulans. J. Ind. Microbiol. 12, 413-416. DOI: 10.1007/BF01569674

Sarian F.D., van der Kaaij R.M., Kralj S., Wijbenga D.J., Binnema D.J., van der Maarel M.J. y Dijkhuizen L. (2012). Enzymatic degradation of granular potato starch by Microbacterium aurum strain B8 A. Appl. Microbiol. Biotechnol. 93, 645-654.

DOI: $10.1007 / \mathrm{s} 00253-011-3436-7$
Sauer J., Sigurskjold B.W., Christensen U., Frandsen T.P., Mirgorodskaya E., Harrison M., Roepstor P. y Svensson B. (2000). Glucoamylase: Structure/function relationships, and protein engineering. Biochim. Biophys. Acta 1543, 275-293.

DOI: 10.1016/S0167-4838(00)00232-6

SEECO (2003). Norma Mexicana NMX-FF-043-SCFI-2003. Productos alimenticios no industrializados para consumo humano-cereal-cebada maltera (Hordeum vulgare L. y Hordeum distichum L.). Especificaciones y métodos de prueba. Secretaría de Economía. Diario Oficial de la Federación, 6 de noviembre.

SIAP (2018). Anuario estadístico de la producción agrícola. Servicio de Información Agroalimentaria y Pesquera [en línea]. http://nube.siap.gob.mx/cierreagricola/ 02/07/2018

Silva M.T., Angelis D.A., Carvalho A.A.F., da Silva R., Boscolo M. y Gomes E. (2005). Production of saccharogenic and dextrinogenic amylase by Rhizomucor pusillus A 13.36. J. Microbiol. 43 (6), 561-568.

Tomasik P. y Horton D. (2012). Enzymatic conversions of starch. Adv. Carbohydr. Chem. Biochem. 68, 59-436. DOI: 10.1016/B978-0-12-396523-3.00001-4

Uthumporn U., Shariffa Y.N., Failah A. y Karim A.A. (2012). Effects of $\mathrm{NaOH}$ treatment of cereal starch granules on the excent of granular starch hydrolysis. Colloid Polym. Sci. 290, 1481-1491.

DOI: $10.1007 / \mathrm{s} 00396-012-2674-2$

Van der Maarel M.J.E.C., van der Veen B., Uitdehaag J.C.M., Leemhuis H. y Dijkhuizen L. (2002). Properties and applications of starch-converting enzymes of the $\alpha$-amylase family. J. Biotechnol. 94, 137-155. DOI: 10.1016/S0168-1656(01)00407-2

Vasanthan T. y Hoover R. (2009). Barley starch: Production, properties, modification and uses. En: Starch: Chemistry and technology (BeMiller J. y Whistler R., Eds.). Elsevier, Amsterdam, pp. 601-625.

Wang L. y Wang Y.J. (2004). Rice starch isolation by neutral protease and high-intensity ultrasound. J. Cereal Sci. 39, 291-296.

DOI: $10.1016 / \mathrm{j} . j \mathrm{cs} .2003 .11 .002$ 